\title{
Terceira etapa do método canguru: experiência de mães e profissionais da atenção primária
}

\author{
The third stage of kangaroo method: experience of mothers and primary healthcare professionals \\ Tercera etapa del método madre-canguro: experiencia de madres y profesionales de atención primaria
}

\author{
Altamira Pereira da Silva Reichert ${ }^{1}$ (1) \\ Anniely Rodrigues Soares ${ }^{1}$ (B) \\ Iolanda Carlli da Silva Bezerra ${ }^{1}$ (1) \\ Anna Tereza Alves Guedes ${ }^{1}$ (D) \\ Rafaella Karolina Bezerra Pedrosa ${ }^{1}$ (]) \\ Daniele de Souza Vieira ${ }^{1}$ (ib
}

1. Universidade Federal da Paraíba. João

Pessoa, PB, Brasil.
Autor(a) correspondente:

Anniely Rodrigues Soares.

E-mail: anniely_rodrigues@hotmail.com.

Recebido em 20/03/2020.

Aprovado em 28/07/2020.

\section{RESUMO}

Objetivo: Compreender a continuidade da terceira etapa do Método Canguru na perspectiva de mães e profissionais de saúde. Método: Trata-se de um estudo qualitativo, exploratório-descritivo, realizado em Unidades de Saúde da Família e nos domicílios de mães canguru em uma capital do nordeste brasileiro. Foram entrevistados doze profissionais de saúde e dez mães-canguru. O material empírico foi submetido à análise temática. Resultados: Emergiram duas categorias temáticas: (Des)conhecimento acerca do Método Canguru e suas ações para a continuidade da terceira etapa; e Entraves à continuidade da terceira etapa do Método Canguru. Conclusão e implicações para prática: Identificou-se o ínfimo conhecimento dos profissionais e das mães acerca do Método Canguru, ausência de capacitação dos profissionais da atenção primária, lacuna na comunicação entre a atenção primária e terciária. Há descontinuidade do cuidado à criança e mãe-canguru após alta hospitalar, pois os profissionais da atenção primária não estão sendo copartícipes no acompanhamento. Conhecer a realidade da terceira etapa do método canguru viabiliza o planejamento de estratégias para superar as dificuldades existentes para continuidade do método e assim ofertar um cuidado qualificado e integral ao binômio mãe-bebê canguru.

Palavras-chave: Método canguru; Atenção Primária à Saúde; Mães; Profissionais de saúde.

\begin{abstract}
Objective: To understand the continuity of the third stage of the Kangaroo Method from the perspective of mothers and health professionals. Method: This is a qualitative, exploratory-descriptive study, carried out in Family Health Units and in the homes of kangaroo mothers in a capital city in northeastern Brazil. Twelve health professionals and ten kangaroo mothers were interviewed. The empirical material was submitted to thematic analysis. Results: Two thematic categories emerged: (Un)knowledge about the Kangaroo Method and its actions for the continuation of the third stage; and Obstacles to the continuation of the third stage of the Kangaroo Method. Conclusion and implications for the practice: The following was identified: minimal knowledge of professionals and mothers about the Kangaroo Method, lack of training for primary care professionals, and a gap in communication between primary and tertiary care. There is discontinuity of care for children and kangaroo mothers after hospital discharge, as primary care professionals are not being co-participants in the follow-up. Knowing the reality of the third stage of the kangaroo method makes it possible to plan strategies to overcome the existing difficulties for continuity of the method and thus offer qualified and comprehensive care to the mother-baby kangaroo binomial.
\end{abstract}

Keywords: Kangaroo-Mother Care Method; Primary Health Care; Mothers; Health professionals.

\section{RESUMEN}

Objetivo: Comprender la continuidad de la tercera etapa del Método Canguro desde la perspectiva de las madres y los profesionales de la salud. Método: Estudio cualitativo, exploratorio-descriptivo, realizado en Unidades de Salud Familiar y en hogares de madres canguro en una capital del noreste de Brasil. Doce profesionales de la salud y diez madres canguro fueron entrevistados. El material empírico fue sometido a análisis temático. Resultados: Surgieron dos categorías temáticas: (Des) conocimiento sobre el Método Canguro y sus acciones para la continuación de la tercera etapa; y Obstáculos a la continuación de la tercera etapa del Método Canguro. Conclusión e implicaciones para la práctica: Se identificó el conocimiento mínimo de profesionales y madres sobre el Método Canguro, la falta de capacitación para profesionales de atención primaria, una brecha en la comunicación entre la atención primaria y terciaria. Hay discontinuidad en la atención de niños y madres canguro después del alta hospitalaria, ya que los profesionales de atención primaria no son copartícipes en el seguimiento. Conocer la realidad de la tercera etapa del método canguro permite planificar estrategias para superar las dificultades existentes para la continuidad del método y ofrecer una atención calificada e integral al binomio canguro madre-bebé.

Palabras clave: Método Madre-Canguro; Atención Primaria de Salud; Madres; Profesionales de la salud. 


\section{INTRODUÇÃO}

A atenção à saúde da criança obteve avanços que colaboraram significativamente para a redução da mortalidade infantil. ${ }^{1} \mathrm{Em}$ nível mundial, destaca-se que entre os anos de 1990 a 2016 o número de mortes de crianças menores de cinco anos reduziu de 12,7 milhões para 5,6 milhões. ${ }^{1}$

No Brasil, o declínio da taxa de mortalidade neonatal não ocorreu com a mesma intensidade como na primeira infância. A mortalidade neonatal no país reduziu de 16,7 óbitos por 1.000 nascido vivos em 2000 , para 9,4 óbitos em 2015 , sendo a prematuridade a principal causa das mortes neonatais. ${ }^{2}$

Sob essa perspectiva, destaca-se a prematuridade como uma condição preocupante que está relacionada diretamente ao óbito neonatal. Cerca de 15 milhões de prematuros nascem a cada ano no mundo, desse quantitativo, um milhão não sobrevive. Estima-se que $75 \%$ dessas vidas poderiam ser salvas com a adoção de cuidados de saúde simples e econômicos. ${ }^{3}$ Assim, a disponibilidade de cuidados qualificados no pré-natal, nascimento e pós-natal são capazes de favorecer a sobrevivência neonatal e a promoção da saúde e bem-estar das crianças prematuras. ${ }^{4}$

Como proposta para redução da mortalidade neonatal, o Ministério da Saúde (MS) do Brasil implementou o Método Canguru (MC). Essa estratégia é desenvolvida em três etapas, a primeira se inicia no pré-natal, passando pelo parto e nascimento e se estende até a internação do RN na Unidade Neonatal; na segunda, a mãe acompanha em tempo integral o filho na Unidade de Cuidados Intermediários Canguru (UCINCa). A terceira etapa consiste na alta hospitalar da criança, com continuidade dos cuidados no domicílio e na Unidade Básica de saúde (UBS), mantendo o vínculo com o hospital de origem até que o peso ideal para a faixa etária seja atingido. ${ }^{5}$

No decorrer de suas etapas, o MC proporciona inúmeros benefícios à saúde das crianças prematuras e/ou de baixo peso, favorecendo o aleitamento materno; o ganho de peso adequado; a melhora a resposta fisiológica, psicoafetiva e neurocomportamental; o desenvolvimento motor e cognitivo; a redução dos níveis de infecção e de reinternações; redução dos níveis de cortisol, da morbimortalidade infantil e de custos para a saúde pública. ${ }^{6-8}$

Para que tais benefícios sejam alcançados é imprescindível o acompanhamento do binômio mãe-bebê nas etapas do MC, porém constata-se que há uma lacuna na continuidade do método no domicílio. Pesquisa com mães de Recém-nascido pré-termo (RNPT) e/ou baixo peso evidenciou que há descontinuidade do cuidado após alta hospitalar, visto que apenas $11,6 \%$ receberam a visita domiciliar dos profissionais da Atenção Primária à Saúde (APS). ${ }^{9}$ Outro estudo identificou fragilidade no conhecimento e ausência de experiência do MC entre os enfermeiros. ${ }^{10}$

Vale ressaltar que a continuidade da terceira etapa do $\mathrm{MC}$ depende do compromisso materno e familiar, bem como da responsabilização da equipe hospitalar e da APS para efetivar o cuidado compartilhado. Portanto, o compromisso da Atenção Básica nessa conjuntura é basilar para incentivar o binômio a dar seguimento ao método e, assim, reduzir agravos a saúde da criança. ${ }^{11}$

Diante da relevância da continuidade do MC na terceira etapa para a efetivação de ações que visem diminuir a mortalidade neonatal, bem como da escassez de estudos que versam sobre a relação entre a APS e o MC, o presente estudo se destaca ao buscar apreender a continuidade da assistência ofertada pela APS ao binômio mãe-bebê canguru. Para isso, emergiu a seguinte questão norteadora: Como está sendo a continuidade da terceira etapa do método canguru? Portanto, o presente estudo teve como objetivo compreender a continuidade da terceira etapa do Método Canguru na perspectiva de mães e profissionais de saúde da Atenção Primária à Saúde.

\section{METÓDO}

Trata-se de um estudo qualitativo, exploratório-descritivo, o qual busca entender e/ou interpretar o significado individual ou coletivo para a vida das pessoas. ${ }^{12}$

O estudo foi desenvolvido nas Unidades de Saúde da Família (USF) pertencentes aos cinco Distritos Sanitários de João Pessoa - PB e nos domicílios de mães-canguru, a partir das seguintes etapas:

$1^{\circ}$ etapa: identificação das mães-canguru e seus respectivos endereços nos registros presentes na Maternidade de referência municipal;

º etapa: comparecimento aos Distritos Sanitários para identificação das USFs em que as mães-canguru estavam cadastradas;

3ํe etapa: contato inicial com as USFs. Nessa oportunidade, os médicos e enfermeiros, responsáveis pelo acompanhamento de saúde da criança, foram informados sobre o objetivo da pesquisa e convidados a participar, bem como foi solicitado à colaboração da equipe de saúde para facilitar o acesso aos domicílios das mães-canguru.

$4^{\circ}$ etapa: realização das entrevistas com os profissionais de saúde no âmbito das USFs e com as mães-canguru em seus respectivos domicílios.

A seleção dos participantes aconteceu por conveniência, por meio de convite presencial realizado pelas pesquisadoras, e contou com a colaboração de dez enfermeiros, dois médicos e dez mães-canguru. Optou-se pelas categorias Médico e Enfermeiro por serem os profissionais da Equipe de Saúde da Família que realizam o acompanhamento da criança na USF.

Os participantes do estudo foram eleitos a partir de alguns critérios: médico ou enfermeiro efetivos ou contratados que estivessem atuando na USF há no mínimo seis meses e que possuíssem RNPT e/ou baixo peso na área de abrangência da unidade; mães inseridas no Método Canguru ou que o vivenciaram em até noventa dias pós-alta hospitalar, independente de ter recebido alta ou não do Método; e mães adscritas às USFs do seu território. 
Foram excluídos profissionais que, no período da coleta de dados, estavam licenciados do trabalho e os que não realizaram atendimento ao binômio criança/mãe-canguru. Quanto às mães, foram excluídas aquelas com limitações cognitivas que dificultavam a realização da entrevista.

Destaca-se a dificuldade em captar as mães-canguru, tendo em vista que a identificação dessas ocorreu em uma maternidade de referência no estado da Paraíba, e muitas não residiam no município sede da pesquisa e, além disso, muitas não foram localizadas a partir dos endereços fornecidos no momento da admissão. Em relação aos profissionais, não se conseguiu uma boa adesão dos médicos para participar da pesquisa, tendo em vista que se recusavam a responder a entrevista, justificando que o enfermeiro era o profissional mais apto para fornecer informações acerca do binômio.

A coleta de dados ocorreu no período de abril a junho de 2018, por meio de entrevista semiestruturada. O roteiro para a entrevista com as mães continha as seguintes questões: "Como foi ou está sendo a continuidade do método canguru no domicílio?" "Em sua opinião, quais fatores interferem ou interferiram na continuidade do método canguru no domicílio?"

Para os profissionais, foram utilizadas as questões:"Relate o que você sabe sobre o MC.", "Conte-me o que você sabe sobre a terceira etapa do método canguru." e "Fale para mim sobre a assistência que você está oferecendo ao binômio mães/recémnascido na terceira etapa do método canguru."

Para a realização das entrevistas foi prezado por ambiente com mínima interferência sonora e de terceiros, a fim de assegurar a privacidade dos participantes. A duração média das entrevistas foi 20 minutos, que foram gravadas em mídia digital para posteriormente serem transcritas na íntegra.

A análise dos dados seguiu os passos propostos por Minayo ${ }^{12}$ para a análise temática, portanto, foram executadas as seguintes etapas: o material coletado nas entrevistas gravadas foi transcrito para realizar a primeira organização das falas em determinada ordem. Nessa fase, traçou-se o mapa horizontal do material. Posteriormente, à luz do referencial teórico, bem como dos objetivos propostos, procedeu-se a leitura exaustiva e repetida, fazendo uma relação interrogativa para apreender as estruturas de relevância. Logo após, foi possível elaborar a categorização por meio da leitura transversal. Em seguida, a partir das estruturas de relevância, houve o enxugamento da classificação, reagrupando os temas mais relevantes.

Vale destacar que foram cumpridas as exigências formais da Resolução no. 466/12 do Conselho Nacional de Saúde (CNS) como a inclusão dos participantes da pesquisa após a assinatura do Termo de Consentimento Livre e Esclarecido (TCLE) que foi entregue em duas vias. Para assegurar o anonimato dos participantes, os registros das falas foram codificados, com a letra "E" para profissionais enfermeiros e "M" para os médicos. Para codificar as mães-canguru foi utilizado o termo "Mãe" seguido pela numeração correspondente à ordem cronológica de realização da entrevista, a saber: Mãe 1, [...] e E1/M1, [...]. O critério de encerramento da coleta foi o de saturação, ou seja, quando o conteúdo apreendido foi suficiente para responder ao objetivo proposto e as informações se repetiam nos discursos sem o acréscimo de novos elementos sobre o fenômeno estudado. ${ }^{13}$

Este estudo é vinculado ao projeto de pesquisa intitulado "Vigilância do desenvolvimento: caminhos e perspectivas para a enfermagem" aprovado pelo Comitê de Ética em Pesquisa do Centro de Ciências da Saúde da UFPB, sob o no de parecer consubstanciado 2.189.497, do ano de 2017.

\section{RESULTADOS}

Entre os doze profissionais participantes da pesquisa, dez eram enfermeiros e dois médicos, com idade entre 27 e 68 anos. Quanto ao tempo de atuação na USF, cinco profissionais atuavam a menos de 10 anos, seis profissionais há mais de 10 anos e um possuía 20 anos de atuação.

Também participaram do estudo dez mães de crianças prematuras e/ou baixo peso, com idade entre 19 e 40 anos. Quanto à profissão, seis mães eram do lar, duas estudantes e duas tinham trabalho formal. Apenas três mulheres eram solteiras, sete eram casadas ou mantinham união estável. A metade das mães tinha apenas um filho. $A$ idade gestacional dos bebês ao nascimento variou entre 26 a 35 semanas.

A partir da análise do material empírico emergiram duas categorias: (Des)conhecimento acerca do Método Canguru e suas ações para a continuidade da terceira etapa; e Entraves à continuidade da terceira etapa do Método Canguru.

\section{(Des)conhecimento acerca do Método Canguru e suas ações para a continuidade da terceira etapa}

Alicerçado nos discursos, foi possível refletir que o acompanhamento das mães-canguru e seus filhos na terceira etapa do MC acontece, majoritariamente, na atenção terciária por meio do serviço ambulatorial, até a criança atingir 2.500 gramas. Isso ocorre devido à orientação repassada pela equipe hospitalar, no momento da alta, sobre a continuidade do MC na APS.

O que acontece é que, quando eu saí da maternidade, eles nos orientaram a voltar à maternidade para fazer todo o acompanhamento lá. (Mãe 4)

Lá (maternidade) eles não disseram que tinha que continuar o método canguru em casa, eu fiz porque eu quis. Não avisaram não. (Mãe 5)

No âmbito da APS, os profissionais que trabalham nesse nível de atenção relataram o que compreendem sobre o MC, suas etapas e, principalmente, a atribuição do serviço na terceira etapa.

O que eu sei é que geralmente o método canguru é usado para aquelas mães que precisam ficar mais tempo na maternidade do que as gestantes ficam. As mães do método canguru são as que têm um parto prematuro ou um parto complicado e utiliza esse método justamente 
para poder iniciar uma amamentação precoce e melhorar o contato da mãe com o bebê. (M2)

É para melhorar o binômio mãe bebê, principalmente a questão do parto humanizado, logo após o parto justamente tentar melhorar o vínculo do bebê com a mãe, ficando em alojamento conjunto, e para esclarecer as dúvidas delas sobre aleitamento materno e deixar o bebê mais próximo após o parto. (M1)

Tenho conhecimento básico que eu vejo nas maternidades, os bebês prematuros que ficam em contato corpo a corpo com a mãe, naquele metodozinho enrolado e que isso vai trazer a temperatura adequada para o bebê, os batimentos cardíacos, respiração vão tudo melhorar e a amamentação. É isso que eu sei. (E1)

Em relação ao Método Canguru, fica evidente nos discursos que algumas mães e profissionais reconhecem alguns benefícios e a importância para o binômio mãe-filho, contudo foi possível identificar que, tanto os profissionais quanto as mães, reduzem o método à posição canguru, considerando-os sinônimos.

(A posição Canguru) Acho que é para ele sentir mais o meu calor, sentir mais que está perto de mim. (Mãe 8)

É uma relação mãe-filho [...] eles desenvolvem bem mais rápido porque é uma gravidez fora da barriga, eles tão ali junto pele a pele, ouvindo os batimentos, a voz da mãe, sendo amamentados a cada necessidade que ele venha a ter, então eu acho muito importante. (E9)

Eu acho importante, é bem interessante também o método e, realmente, eu acredito que é um fator positivo no ganho de peso, no desenvolvimento da criança. (Mãe 10)

Quando a mãe e o pai colocam neles (Posição do MC), a criança fica mais calma, reduz o estresse, a criança se torna mais protegida, então esse método canguru é de suma importância. (E4)

Nesse contexto, os profissionais de saúde quando questionados sobre suas condutas para uma criança prematura referem que diminuem o intervalo entre as consultas de puericultura.

É a mesma, só que a gente pega e diminui o espaçamento de consultas, chama o agente de saúde, a gente vai direto lá, faz a primeira consulta quando a mãe já tá em casa com o bebê, a visita puerperal, e já marca 15 dias para cá (USF), aí fica mês a mês fazendo o acompanhamento do crescimento e desenvolvimento dessa criança. (E5) Com relação ao método canguru em si não tem nada especifico aqui na unidade, mas as crianças prematuras podem iniciar mais cedo o acompanhamento da puericultura, sempre tem a visita da enfermeira na primeira semana, mas isso é para todos, se tiver alguma coisa mais assim que precise de mim, ela me chama. (M2)
Alguns enfermeiros mencionaram a falta de capacitação dos profissionais da APS sobre o MC e de comunicação entre a unidade e a maternidade.

Infelizmente, aqui na ponta, a gente não recebe nenhum treinamento, nenhuma orientação sobre como acontece o método canguru, a gente sabe sim que é um projeto que se tem dentro da maternidade, entretanto, não há essa interlocução da atenção terciária com a atenção primária. (E2)

[...] Olha a gente não teve nenhum treinamento, nenhum curso. A gente não chegou a ir no hospital, que era bom que a gente tivesse uma experiência dessa de hospital. Eu sei aquilo que li, que tem esse preparo com as mães de criança com baixo peso e é isso que sei, mas assim para ver, participar nenhum de nós tem cursos. (E8)

\section{Entraves à continuidade da terceira etapa do Método Canguru}

A assistência ao binômio mãe-bebê na APS, no que se refere ao MC, enfrenta diversos obstáculos que interferem a continuidade do cuidado. A princípio, os relatos dos profissionais de saúde e das mães indicam o cuidado que é ofertado pela APS e o comprometimento do seu papel como copartícipe na terceira etapa do MC.

Eu só ia para (Maternidade $X$ ) fazer o acompanhamento toda semana. (Mãe 5)

Estou sendo acompanhada só por um mesmo, pela maternidade [...] (Mãe 6)

Eu não atuo muito (no $M C$ ), até porque se ela está lá na atenção terciária, a grande maioria não volta pra dizer como é que está. (E4)

Depois que ela saiu da maternidade, a pouca assistência que a gente prestou foi em relação ao crescimento e desenvolvimento só. Então, verifica peso, perímetro cefálico, perímetro torácico, foi o mais simples que a gente pôde fazer. (E5)

Ademais, os profissionais da APS também referiram a ausência de informações sobre a puérpera e o seu filho após o parto, dificultando a realização da visita domiciliar. Por sua vez, as mães mencionaram a inexistência das visitas pelos profissionais.

Geralmente quando a mãe não tem ajuda para cuidar do bebê, ela vai para o interior e não ficamos sabendo do nascimento. Elas só ficam em casa quando vem um parente ajudar, mas mesmo assim somos informados tardiamente. (E1)

Eu vim saber após dois meses que ela tinha tido esse parto prematuro, porque elas não comunicam, elas vão embora da área, vão pra casa da sogra ou pra casa da 
tia, da mãe, e só voltam pra área quando o bebê já tá com dois meses, três meses. Então esse acompanhamento do método canguru, a gente não tem. (E9)

Eu já procurei o postinho [...] Ainda não recebi visita de nenhum profissional. (Mãe 6)

Não houve visita na minha casa de nenhum profissional de saúde. (Mãe 4)

Outro problema exposto foi a ausência de comunicação entre os pontos de atenção à saúde. Isso é observado quando os participantes do estudo relatam a falta de contrarreferência do serviço hospitalar para a USF.

O que a gente sabe é que a criança esteve no método canguru e já saiu, já recebeu alta, não vem nenhuma contrarreferência da maternidade para atenção primária, parece que rompe-se ali. Então quando a gente faz a visita puerperal percebemos que a maioria dos resumos de alta não são preenchidos e não vem com o roteiro que deveria. (E2)

Não teve contrarreferência, eu vim saber agora por você (que tem bebê canguru na área de abrangência da USF). (E6)

\section{DISCUSSÃo}

A partir dos relatos analisados foi possível elucidar o reduzido conhecimento sobre o $\mathrm{MC}$ dos profissionais da APS e das mães-canguru e que suas experiências são marcadas por entraves que resultam na descontinuidade do $\mathrm{MC}$ no domicílio. O nascimento de um bebê prematuro e sua hospitalização desencadeiam nas mães e no seu núcleo familiar sentimentos de tristeza e insegurança pela vida e condição da criança. ${ }^{14}$

Assim, é basilar que o binômio mãe-bebê seja apoiado integralmente ao retornar para o domicílio, haja vista que se inicia a última etapa do MC. Desse modo, o suporte dos profissionais de saúde deve ocorrer com maior intensidade com o objetivo de orientar a puérpera, torná-la mais segura, tranquila, além de estimular uma rede de apoio afetiva e empática, valorizando as boas condutas e oferecendo auxílio quando necessário. ${ }^{11}$

Ressalta-se que a orientação da puérpera e seus familiares sobre o MC deve perpassar por todo o processo de internação, inclusive no momento da alta hospitalar. ${ }^{11}$ Tais orientações são cruciais para favorecer a continuidade do $\mathrm{MC}$ na atenção primária e terciária, contudo observa-se nas falas das participantes que os profissionais da maternidade remetem a continuidade do cuidado do bebê de risco apenas ao serviço ambulatorial, suprimindo o compartilhamento do cuidado com a APS.

Sobre isso, estudo desenvolvido no Rio de Janeiro menciona que há uma relação de dependência entre as crianças com necessidades especiais de saúde e o hospital, visto que, diante de qualquer evento adverso após a alta hospitalar, há o retorno destas à atenção terciária. Frente a isso, os profissionais do serviço terciário justificam a ausência do compartilhamento do cuidado com a APS devido a fragmentação da Rede de Atenção à Saúde. ${ }^{15}$

Frente ao vulnerável acompanhamento da criança e mãecanguru no domicílio, os relatos dos participantes elucidaram o ínfimo conhecimento acerca do Método Canguru, tanto dos profissionais de saúde quanto das mães, e do papel da APS para a continuidade do cuidado. Assim, percebeu-se que esse problema é um dos motivos que fragilizam a assistência ao binômio mãe-filho na última etapa do MC.

Corroborando o exposto, estudo identificou a compreensão superficial dos profissionais da atenção primária sobre o MC, limitando seu conhecimento apenas ao contato pele a pele e ao vínculo proporcionado pelo método. ${ }^{16}$ Outro estudo realizado com mães evidenciou o conhecimento materno superficial ou até mesmo equivocado acerca do método, ao associá-lo apenas à posição canguru e criação de vínculo, ${ }^{17}$ como identificado no presente estudo.

No que tange aos profissionais, o reflexo da falta de conhecimento e compreensão superficial acerca do método, é a insegurança para realizar a terceira etapa do MC. ${ }^{16}$ Estudo desenvolvido em Gana com mães de recém-nascidos de baixo peso constatou a falta de preparo dos profissionais de saúde e insatisfação materna com a assistência dos profissionais de saúde, pois consideraram a necessidade de melhor aconselhamento da equipe de saúde sobre cuidados básicos ao RN e a manutenção método mãe-canguru. ${ }^{18}$

Na perspectiva de assistir o binômio na terceira etapa do MC, os profissionais da APS relataram apenas aumentar a frequência das consultas de puericultura e não mencionaram se quer orientar as mães para a continuidade do método no domicílio, sugerindo que eles desconhecem os pressupostos do MC.

Além das consultas, é primordial que os profissionais busquem contemplar as reais necessidades do binômio mãebebê, com apoio do núcleo familiar na efetivação das ações do Método Canguru no domicílio. ${ }^{5} \mathrm{~A}$ equipe da $\mathrm{AB}$ precisa, também, estar inteirada acerca do método, orientando sobre os cuidados cotidianos com o bebê e a importância da continuidade da método e da posição canguru, mesmo que a mãe-canguru e seu filho sejam acompanhados pela maternidade. ${ }^{4}$

Neste norte, os profissionais mencionaram que não receberam nenhum tipo de capacitação acerca do MC, lacuna que dificulta a efetivação do seguimento ao método na atenção primária. Realidade semelhante foi encontrada em estudo desenvolvido com enfermeiras da atenção terciária ao sinalizar a necessidade de capacitações para os profissionais, diante do conhecimento superficial sobre o MC, suas etapas e propostas. ${ }^{19}$ Assim, percebese a necessidade de estratégias de capacitações e treinamentos para os profissionais da APS, a fim de possibilitar o seguimento da terceira etapa do MC com segurança e responsabilização pelo cuidado por partes dos médicos e enfermeiros. 
De acordo com os relatos, a omissão dos profissionais da APS na etapa que também lhes compete é um entrave alarmante à continuidade do $\mathrm{MC}$ no domicílio. Sobre isso, estudo aponta a negligência da Atenção Básica no acompanhamento de mães e bebês-canguru após a alta hospitalar e enfatiza que a descontinuidade do acompanhamento é preocupante, tendo em vista que gera prejuízos à saúde da criança e da família, resultando em um cuidado solitário ao bebê fornecido pelas mães, sem o apoio dos profissionais de saúde. ${ }^{9}$

Assim, é primordial o compartilhamento das responsabilidades entre os profissionais da atenção hospitalar e atenção primária, a fim de evitar a descontinuidade do método, como também, promover a redução da morbimortalidade infantil. ${ }^{4}$

Somado a isso, destaca-se nas falas dos profissionais da APS a não realização da visita domiciliar por falta de comunicação, sobretudo porque no período da coleta de dados, todos os bebês canguru estavam em seu domicílio há mais de 15 dias e não houve nenhuma visita e nem intervenção relacionada ao método, o que vem a comprometer a continuidade da terceira etapa do MC e, por conseguinte, a integralidade do cuidado.

As visitas domiciliares pela equipe da atenção primária, configuram uma ferramenta importante para conhecimento, orientação e ensinamentos, sobretudo para uma mãe de criança prematura ${ }^{4} \mathrm{Tal}$ estratégia proporciona a avaliação e incentivo à implementação da terceira fase do MC, além disso pode contribuir para a adaptação familiar ao bebê prematuro, sendo fonte de apoio para o desenvolvimento de cuidado ao recém-nascido e reduzindo ocorrências de reinternações. ${ }^{20}$

Nesse contexto, compreende-se que a comunicação entre os serviços no momento da alta hospitalar reduziria a fragmentação do cuidado e a transferência de responsabilidades dos profissionais da APS para as mães-canguru no que tange ao contato inicial com o serviço. Seguramente, o compartilhamento do cuidado e a comunicação entre os serviços trazem benefícios tanto para as mães, que terão mais segurança e não se sentirão desamparadas após alta hospitalar, quanto para os profissionais de saúde, que terão respaldo sobre os acontecimentos acerca da saúde da criança nos níveis de atenção utilizados. ${ }^{21}$

Nessa perspectiva, estudo desenvolvido no Paquistão, evidenciou que o apoio ofertado pelos profissionais de saúde ao binômio mãefilho foi considerado fator primordial para assegurar o seguimento do MC no domicílio. ${ }^{22}$ Sobre essa continuidade da atenção, pesquisa desenvolvida na província de Quebec apontou os enfermeiros de ligação como fundamentais para que os níveis de atenção à saúde possam operar como uma rede, de forma articulada e coerente. Isso é possível pois os enfermeiros desenvolvem ações centradas nas necessidades do paciente e em articulação com os serviços extra-hospitalares, assegurando a continuidade da assistência aos pacientes após a alta hospitalar. ${ }^{23}$

Assim, a implementação dos enfermeiros de ligação no contexto brasileiro emerge como uma estratégia promissora que poderá minimizar a descontinuidade do cuidado por ocasião da alta hospitalar.

\section{CONCLUSÃO E IMPLICAÇÕES PARA PRÁTICA}

Ao analisar as experiências de mães e profissionais de saúde na terceira etapa do MC, foram identificados entraves que resultam na descontinuidade do método no domicílio. Os discursos desvelam o limitado e até ausente conhecimento dos profissionais e das mães acerca do método e seu seguimento na terceira etapa, como também, a centralização do atendimento à criança e mãe-canguru no nível terciário, a fragilidade do cuidado compartilhado entre a APS e a atenção hospitalar, a necessidade de capacitação e educação permanente dos profissionais, a lacuna na efetivação da visita domiciliar e a falta de comunicação entre $a$ atenção primária e terciária.

Como limitações do estudo, considera-se a inclusão de binômios de apenas uma maternidade, bem como a escolha das categorias de nível superior (médico e enfermeiro). Todavia, não se pretendia generalizar os resultados, mas conhecer a realidade com profundidade. Espera-se que este estudo estimule os profissionais de saúde atuantes no nível primário e terciário da atenção a repensarem suas práticas no acompanhamento de saúde da criança prematuras e/ou de baixo peso e seus familiares, a fim de promover a continuidade do cuidado na terceira etapa do MC, enfatizando a participação da APS e suas potencialidades. Ademais, recomenda-se o desenvolvimento de pesquisas de intervenção com o foco na capacitação dos profissionais de saúde, com o propósito de identificar se, a partir do conhecimento, esses profissionais serão promotores do MC nos diferentes níveis de atenção.

\section{FINANCIAMENTO}

Bolsas do Programa Institucional de Iniciação Científica financiadas pelo Conselho Nacional de Desenvolvimento Científico e Tecnológico (CNPq) concedidas à Anniely Rodrigues Soares e lolanda Carlli da Silva Bezerra, período agosto 2017 a julho 2018, à pesquisa "Vigilância do desenvolvimento infantil: caminhos e perspectivas para a Enfermagem", coordenado por Altamira Pereira da Silva Reichert.

\section{CONTRIBUIÇÕES DOS AUTORES}

Desenho do estudo. Altamira Pereira da Silva Reichert. Coleta ou produção dos dados. Anniely Rodrigues Soares. Iolanda Carlli da Silva Bezerra.

Análise de dados e interpretação dos resultados. Altamira Pereira da Silva Reichert. Anniely Rodrigues Soares. Iolanda Carlli da Silva Bezerra. Anna Tereza Alves Guedes. Rafaella Karolina Bezerra Pedrosa. Daniele de Souza Vieira.

Redação e revisão crítica do manuscrito. Aprovação da versão final do artigo. Responsabilidade por todos os aspectos do conteúdo e a integridade do artigo publicado. Altamira Pereira da Silva Reichert. Anniely Rodrigues Soares. Iolanda Carlli da Silva Bezerra. Anna Tereza Alves Guedes. Rafaella Karolina Bezerra Pedrosa. Daniele de Souza Vieira. 


\section{EDITOR ASSOCIADO}

\author{
Eliane Tatsch Neves
}

\section{REFERÊNCIAS}

1. Fundo das Nações Unidas para Infância. Levels and Trends in Child Mortality - Report [Internet]. Brasília: UNICEF;2017 [citado 8 jan 2018] Disponível em: https://data.unicef.org/resources/levels-trends-childmortality/

2. Ministério da Saúde (BR). Indicadores e Dados Básicos. Taxa de mortalidade neonatal [Internet]. Brasília: Ministério da Saúde; 2012 [citado 20 abr 2020]. Disponível em: http://tabnet.datasus.gov.br/cgi/ idb2012/c0104.htm

3. World Health Organization. Preterm Birth [Internet]. Geneva:WHO;2018 [citado 5 jan 2019]. Disponível em: http://www.who.int/mediacentre/ factsheets/fs363/en/

4. World Health Organization. Newborns: reducing mortality [Internet]. Geneva:WHO;2019 [citado 25 abr 2020]. Disponível em: https://www. who.int/news-room/fact-sheets/detail/newborns-reducing-mortality

5. Ministério da Saúde (BR), Secretaria de Atenção à Saúde. Método Canguru: manual da terceira etapa do Método Canguru na Atenção Básica [Internet]. Brasília: Ministério da Saúde; 2018 [acesso em 25 nov 2019]. Disponível em: http://bvsms.saude.gov.br/bvs/publicacoes/ manual_terceira_etapa_metodo_canguru.pdf

6. Bilotti CC, Gomes ES, Bianchi AB, Bolsoni LLM, Santos SMA, Bernuci MP. Método mãe canguru para recém-nascidos de baixo peso: revisão da literatura. Saúde e Pesquisa. 2016;9(3):587-95. https://doi. org/10.17765/2176-9206.2016v9n3p587-595.

7. Chagas MA, Almeida NMS, Costa MML, Bastos LP. Percepção das mães acerca da vivência do Método Canguru. Rev Elet FAINOR 2017;10(3):424-35. http://dx.doi.org/10.11602/1984-4271.2017.10.3.12.

8. Santos MH, Azevedo Fo FM. Benefícios do método mãe canguru em recém-nascidos pré-termo ou baixo peso: uma revisão da literatura. Rev Bras Ciências da Saúde. 2016;14(1):68-76. https://doi.org/10.5102/ ucs.v14i1.3477.

9. Feitosa MR, Gubert FA, Tomé MABG, Pinheiro MTM, Neves CS, Benevides JL et al. Primary health care follow-up visits: investigation of care continuity of preterm newborns from a Kangaroo-Mother Care Unit. Int Arch Med. [Internet]. 2017; [citado 2 dez 2019];10(32):1-9. Disponível em: https://www.researchgate.net/publication/314247252 Primary Health_Care_Follow-Up_Visits_Investigation_Of_Care_Continuity_ Of_Preterm_Newborns_From_A_Kangaroo-Mother_Care_Unit

10. Ferreira DDO, Silva MPC, Galon T, Goulart BF, Amaral JBD, Contim D. Método canguru: percepções sobre o conhecimento, potencialidades e barreiras entre enfermeiras. Esc Anna Nery. 2019;23(4):1-7. http:// dx.doi.org/10.1590/2177-9465-ean-2019-0100.

11. Ministério da Saúde (BR), Secretaria de Atenção à Saúde. Atenção humanizada ao recém-nascido: Método Canguru: manual técnico [Internet]. Brasília: Ministério da Saúde; 2017 [citado 3 dez 2019].
Disponível em: http://bvsms.saude.gov.br/bvs/publicacoes/atencao_ humanizada_metodo_canguru_manual_3ed.pdf

12. Minayo MCS. O desafio do conhecimento: pesquisa qualitativa em saúde. 10ª ed. São Paulo: HUCITEC; 2014.

13. Minayo MCS. Amostragem e saturação em pesquisa qualitativa: consensos e controvérsias. Revista Pesquisa Qualitativa. [Internet]. 2017; [citado 10 ago. 2019];5(7):1-12. Disponível em: https://edisciplinas.usp. br/pluginfile.php/4111455/mod_resource/content/1/Minayosaturacao. pdf

14. Heck GMM, Lucca HC, Costa R, Junges CF, Santos SV, Borck M Compreensão do sentimento materno na vivência no método canguru. Revista de Enfermagem da UFSM. 2016;6(1):71-83. http://dx.doi org/10.5902/2179769218083.

15. Góes FGB, Cabral IE. A alta hospitalar de crianças com necessidades especiais de saúde e suas diferentes dimensões. Rev enferm UERJ. 2017;25:e18684. http://dx.doi.org/10.12957/reuerj.2017.18684.

16. Aires LCP, Santos EKA, Costa R, Borck M, Custódio ZAO. Seguimento do bebê na atenção básica: interface com a terceira etapa do método canguru. Rev Gaúcha Enferm. 2015;36(no. esp.):224-32. http://dx.doi. org/10.1590/1983-1447.2015.esp.56805.

17. Dantas JM, Leite HC, Querido DL, Esteves APV, De Almeida VS, Melo MM et al. Percepção das mães sobre a aplicabilidade do Método Canguru. Rev. enferm. UFPE on line. 2018;12(11):2944-951. http:// dx.doi.org/10.5205/1981-8963-v12i11a235196p2944-2951-2018.

18. Schuler C, Ntow GE, Agbozo F. Mothers' experiences with neonatal carefor low birth weight infants at home; a qualitative studyi in the Hohoe Municipality, Ghana. J Pediatr Nurs. 2019;45:e-44-52. http:// dx.doi.org/10.1016/j.pedn.2018.12.017. PMid:30660426.

19. Ferreira DO, Silva MPC, Galon T, Goulart BF, Amaral JB, Contim D. Método canguru: percepções sobre o conhecimento, potencialidades e barreiras entre enfermeiras. Esc Anna Nery. 2019;23(4):e20190100. http://dx.doi.org/10.1590/2177-9465-ean-2019-0100.

20. Nazareth IV, Santos IMM, Silva, LR, Moraes SRL, Silva, ÍR. Riscos gestacionais e o nascimento prematuro: enfrentamento para a maternagem. Rev enferm UFPE on line. [Internet]. 2019; [citado 22 out 2019];13(4):1030-9. Disponível em: https://periodicos.ufpe.br/revistas/ revistaenfermagem/article/download/237885/31803

21. Aires LCP, Santos EKA, Bruggemann OM, Backes MTS, Costa R Referência e contrarreferência do bebê egresso da unidade neonatal no sistema de saúde: percepção de profissionais de saúde da Atenção Primária. Esc Anna Nery. 2017;21(2):e20170028. http://dx.doi. org/10.5935/1414-8145.20170028

22. Jamali QZ, Shah R, Shahid F, Fatima A, Khalsa S, Spacek J et al. Barriers and enablers for practicing kangaroo mother care (KMC) in rural Sindh, Pakistan. PLoS One. 2019;14(6):e0213225. http://dx.doi. org/10.1371/journal.pone.0213225. PMid:31206544.

23. Aued GK, Bernardino E, Lapierre J, Dallaire C. Atividades das enfermeiras de ligação na alta hospitalar: uma estratégia para a continuidade do cuidado. Rev. Latino-Am. Enfermagem. 2019;27:e3162. http://dx.doi. org/10.1590/1518-8345.3069.3162. 